\title{
Alpha-2 Macroglobulin Measurement
}

National Cancer Institute

\section{Source}

National Cancer Institute. Alpha-2 Macroglobulin Measurement. NCI Thesaurus. Code C80168.

The determination of the amount of alpha-2 macrog lobulin present in a sample. 